\title{
Simulating the Various Subsystems of a Coal Mine
}

\author{
Victor Okolnishnikov \\ Siberian Branch of the Russian \\ Academy of Sciences \\ Design Technological Institute of \\ Digital Techniques \\ Novosibirsk, Russia \\ okoln@mail.ru
}

\author{
Sergey Rudometov \\ Siberian Branch of the Russian \\ Academy of Sciences \\ Design Technological Institute of \\ Digital Techniques \\ Novosibirsk, Russia \\ rsw@academ.org
}

\author{
Sergey Zhuravlev \\ Siberian Branch of the Russian \\ Academy of Sciences \\ Design Technological Institute of \\ Digital Techniques \\ Novosibirsk, Russia \\ s-zhur@yandex.ru
}

\begin{abstract}
A set of simulation models of various subsystems of a coal mine was developed with the help of a new visual interactive simulation system of technological processes. This paper contains a brief description of this simulation system and its possibilities. The main possibilities provided by the simulation system are: the quick construction of models from library elements, 3D representation, and the communication of models with actual control systems. These simulation models were developed for the simulation of various subsystems of a coal mine: underground conveyor network subsystems, pumping subsystems and coal face subsystems. These simulation models were developed with the goal to be used as a quality and reliability assurance tool for new process control systems in coal mining.
\end{abstract}

Keywords-coal mining; simulation system; visual interactive simulation; hardware-in-the-loop

\section{INTRODUCTION}

One of the future developments of simulation is to create very detailed simulation models with wide application "from the box", with the minimum involvement of simulationists and the maximum involvement of field engineers. Especially in underground mining, it is frequently reported that resources become less available, and harder to be extracted. The technologies of coal mining are well-known. Today mine uses mining machinery for mining, transportation, roof support, etc. Key topics of interest are the detailed description of machines' functionality, the definition of the exact additional machines that may be required, the calculation of the "total cost ownership" of machines, the comparison of the use of big universal machines to the use of more smaller and specialized ones and ultimate product cost definition. These tasks can be solved through the use of computer-based simulation of the coal mining process. These simulation tasks are known as "what-if" ones. The main issue with that particular mining is that it is effective in terms of minimum costs and maximum productivity only if it is planned correctly. Usually a big scheme layout contains various components from different vendors interconnected. That makes it hard or, even, impossible to predict the exact effectiveness. This situation gets worse if there is also a requirement to create new components. Due to the importance of these problems, there is a large number of papers on the use of simulation in the development and optimization of coal mining systems [1-8]. There is also a large number of simulation tools, both universal simulation systems and specialized systems, and packages for the simulation of coal mining systems. While lots of simulation tools solve the "what-if" problem, there is significantly less such tools that allow building integrated simulation for mines hardware development.

A number of models for various technologies of coal mining were developed with the help of a developed simulation system. These models are used for the developing of process control systems for underground coal mines in Kuznetsk Coal Basin (Russia, Western Siberia). The models include both "what-if" tasks and development of hardware for control systems.

\section{TECHNOLOGIES OF COAL MINING}

There are several well-known technologies of coal mining.

\section{A. Longwall Mining}

Longwall mining system is a highly-automated, very powerful and productive way to mine. It is most-widely applied around the world. Its main advantage is that it leaves almost no product inside mines. But it is limited with the depth of the mine (measured from the surface). Also it is applied in relatively flat areas of coal, from 0.8 up to 10 meters high, from 150 to 450 meters face, and up to 4 kilometers in depth. A basic longwall system consists (at least) of an armored face conveyor (AFC), a shearer and roof support sections. The AFC is connected to an outbound belt conveyor. The shearer cuts the product from coal seam face, in a series of passes along the AFC. The AFC delivers products to the belt conveyor. The roof support moves itself and the AFC, pushing it (and itself) forward with hydraulics. One of the problems of longwall mining is roof caving. This can lead to serious environmental problems. Another problem is that longwall requires significant amount of work to be done before its massive equipment is installed in production. This work must be planned as well. One more problem includes a functioning of specialized signaling tools and control systems that monitor marsh gas level, dust level and ventilation facilities. If any of the 
monitored parameters exceed certain save values, the mining usually stops. The reason is usually not obvious for personnel in mines (gas has no smell, dust does not look dangerous) and it can result in turning off the monitoring systems by mine personnel in order to increase the mining. Simulation can help decide the sufficient levels of ventilation that guarantee safe and efficiency.

\section{B. Highwall Mining}

In case when it is impossible to use longwall, a relatively new technology can be applied, named highwall. This is a shearer tool, mounted on the top of the chain of special sections. These sections can be updated to each other, making a long (up to 300 meters) support chain for a shearer. Each section can transport the product developed by the shearer to the end of a sections chain. The shearer and the chain of sections cut the product (coal) from the very thin and curved seams. This is the main advantage of the Highwall technology.

\section{Coal Mining of Flat-Laying Coal Seam}

This approach uses a number of front-cutting mining machines that cut a coal on a special scheme, and a number of self-moving wagons that move a coal from mining machines to the storage area. It solves the same problem as highwall mining, but requires no specialized equipment. Also this approach can be used in deep mining.

\section{THE SIMULATION SYSTEM}

The visual interactive Manufacturing and Transportation Simulation System (MTSS) has been developed at the Design Technological Institute of Digital Techniques of Siberian Branch of the Russian Academy of Sciences (DTIDT) [9, 10]. It is a process-oriented discrete simulation system intended to aim the development and execution of models of technological processes. MTSS is a set of interfaces for creating elementary models and for forming complex models. The elementary models are ready-to-use submodels of an equipment unit with capability of low-level control. A model in MTSS is created by graphical connection of images of elementary models.

The elementary model consists of the following parts:

- Two-dimensional and three-dimensional graphic images.

- Input and output parameters.

- Functionality algorithm describing dependence between parameters.

- States which the elementary model can reach during the simulation process.

- Control commands defining switching process between elementary models states.

MTSS is also a tool for simulating complex models. Statistics are also available as a short overview when model runs, and more statistics are available after model completion. This simulation system is effective in providing an easy-to-use tool for the rapid creation of simulation models by mining engineers. Usually field engineers do not have enough expertise in software simulation but they are capable to connect correctly elementary models to create the required topology.

MTSS uses 2D for the graphical editor and 2D and 3D for the visualization of the running model. Such approach seems more natural for mining engineers, when all installations and machines appear first on 2D plans. 3D is more useful for visualizing complex vertical movement. Process control systems often have two levels: the low level of equipment and simple control logic and the upper level of complex control of production. Therefore one of the distinguishing features of MTSS is a separation of the logic of simulation model into two parts: low-level logic and upper level logic. Such separation allows us not only to correspond to the usual structure of the process control systems but to use such models for embedding them into actual process control systems in the following ways: to emulate equipment, to simulate upper level logic and to send commands to actual process control system for debugging and testing. This separation into upper and lower logics also allows organizing a switch between various implementations of the decomposition. Further, it allows coexisting simulation of upper level logic and a proxy that allows communicating with the upper level logic of actual process control system.

The coal mining model can communicate with a new process control system developed in DTIDT, to be a source of input signals, emulate equipment, test actual control program with simultaneous visualization of overall process of mining. This allows debugging and tuning of a new process control system in accordance with the behavior of the simulated system, even simulating various accidents. This allows minimizing time and costs on site for commissioning.

\section{SIMULATION OF UNDERGROUND CONVEYOR NETWORK}

After mining, products are transported by the net of conveyors to the enterprise storage. A fragment of the conveyor network model is shown in Figure 1. The conveyor network model consists of elementary models of belt conveyors and bunkers and requires a simulation model of power supply to function. Elementary model of belt conveyor is built with the simulation of functionality of its components, such as: structure and belt, drive station, control equipment. The developed model can provide technological processes, control algorithms and the simulation of real information and control signals for the process control system.

The main parameters for elementary model of belt conveyor are the following:

- Position in space.

- Conveyor maximum load.

- Drive parameters (amount of motors, capacity, etc.).

- State (accelerates, work, decelerate, and stop).

- Set of analog (belt speed, energy consumption, etc.) and discrete parameters (inspection of tape returns, cable-role switch, etc). This parameters value is defined from EM simulation data.

- Some service parameters and etc. 
With the help of conveyor network model the following problems for the actual process control system were solved:

- Centralized turning on of conveyors in the direction opposite to a coal flow.

- Turning on of a conveyor after the achievement of required speed of a previous conveyor.

- Turning on of conveyors in defined operating mode.
- Regulation of the speed of a conveyor belt depending on coal size.

- Emergency turning off of a whole conveyor network by turning off of all conveyors simultaneously (halt of the conveyor network, for example, if a methane level is high).

- Optimizing of the energy consumption (lowering of energy consumption needed by conveyor network to work).

- Creation of tools to train the coal mining personnel.

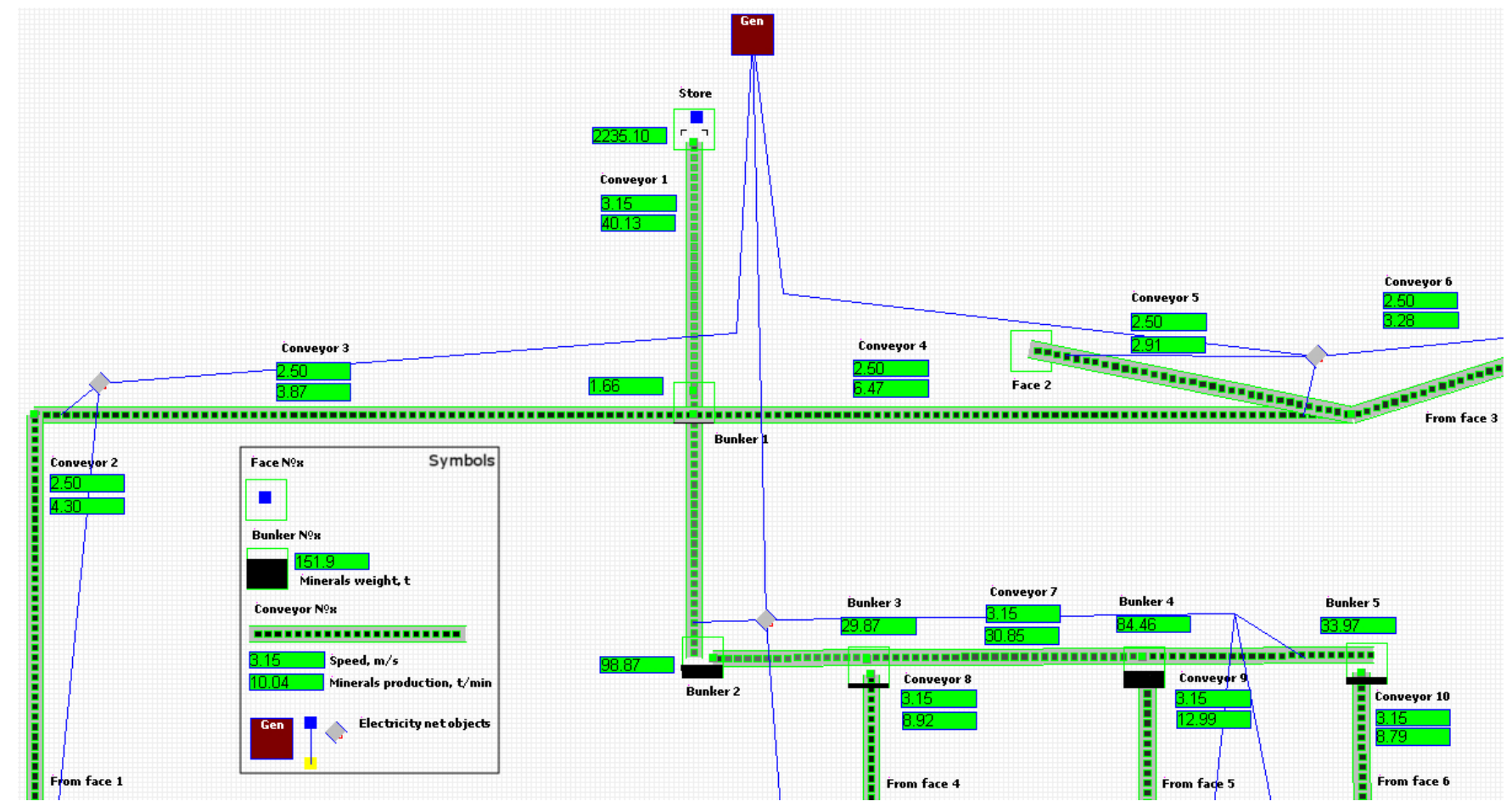

Fig. 1. The fragment of the model of conveyor network.

\section{SIMULATION OF PUMPING SUBSYSTEM}

A fragment of the model of the pumping subsystem is shown in Figure 2. This subsystem refers to mine safety systems. It averts mine flood. Pumping subsystem model consists of pumps, tubes, tanks, water flows and requires elements of the electricity subsystem. Pumping simulation is based on two parts: fluid distribution and energy consumption simulation. The simulation model of this subsystem provides technological and underground water pumping out processes and energy consumption simulation.

The main settings are the following: pump efficiency, tube throughput, pump energy consumption, tanks capacity, and etc. The following problems were solved with the help of the model of pumping subsystem:

- Pumps centralized turning on.

- Pump turning on in according with selected control mode.

- Selection of optimized control mode for pumps.

\section{SIMULATION OF COAL MINING IN VARIOUS TYPES OF COAL SEAMS}

A specialized library of simulation models of mining machines for coal mining was developed. This library is a part of MTSS and its prime goal is to simulate interactively and visualize various aspects of coal mining in flat-lying coal seam.

The library consists of new elementary models of:

- Highwall mining system.

- Longwall mining system.

- Coal seam.

- Mining machines.

- Self-moving coal wagon.

- Storage area.

The library contains also a simulation model of a flat-lying coal seam. This model is a source of the product in a simulation 
model, while storage area is a consumer of a product. The product itself is coal. These new components can communicate with existing libraries of MTSS [11-13] which simulate mines subsystems like:

- Belt conveyor subsystem.

- Power supply subsystem.

- Ventilation subsystem.
A simulation model of coal mining subsystem in a flatlying coal seam was developed using the library of mining machines. Figure 3 contains a sample layout in the simulation model of the flat-lying coal seam (2D and 3D view combined in different views). The simulation model built from the content of the library will simulate the movement of all mobile objects of the model. Both 2D (top view) and 3D visualization are available. Statistical data are also collected.

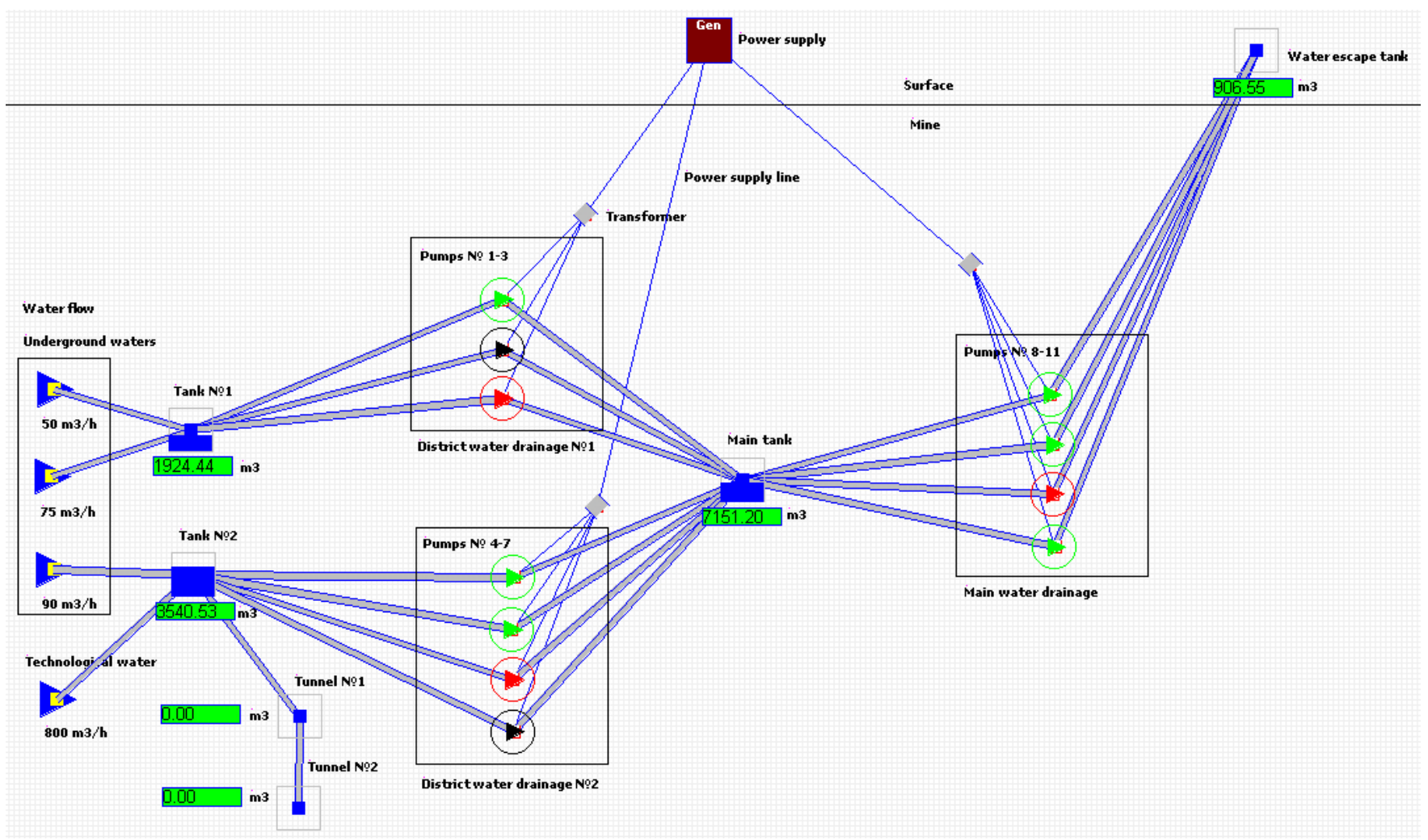

Fig. 2. The fragment of the model of pumping subsystem.

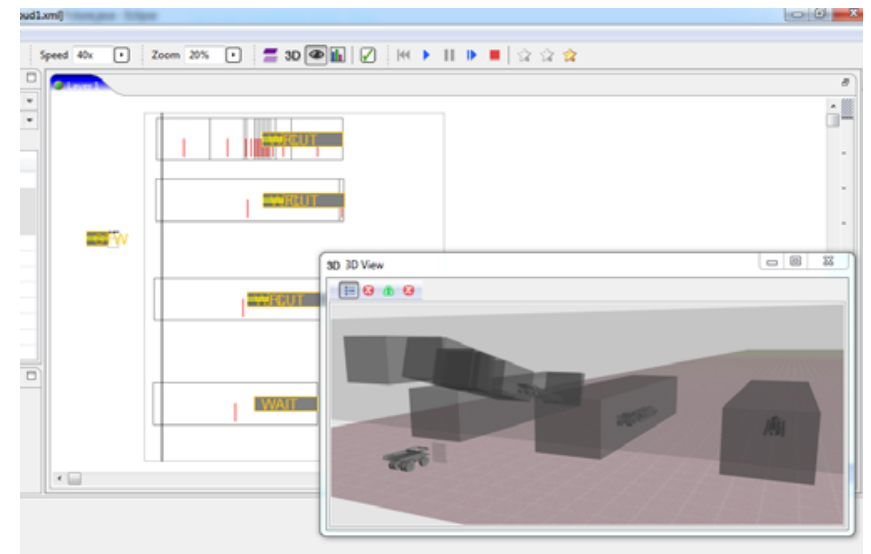

Fig. 3. The simulation model of coal mining in flat-lying coal seam (4 mining machines and 4 self-moving coal wagons).
Figure 4 shows a sample layout in another simulation model of the flat-lying coal seam. The main window consists of 6 areas:

(1) 2D top view. It contains: main mine, side mines. The origin coordinates is at the left top corner of this view.

(2) $3 \mathrm{D}$ view. On Figure 4 there is a view from point 3.

(3) Point of view for the 3D.

(4) Parameters of a simulation model.

(5) Specialized view for fast navigation in simulation model.

(6) Settings for the time start, time end and current model time. 


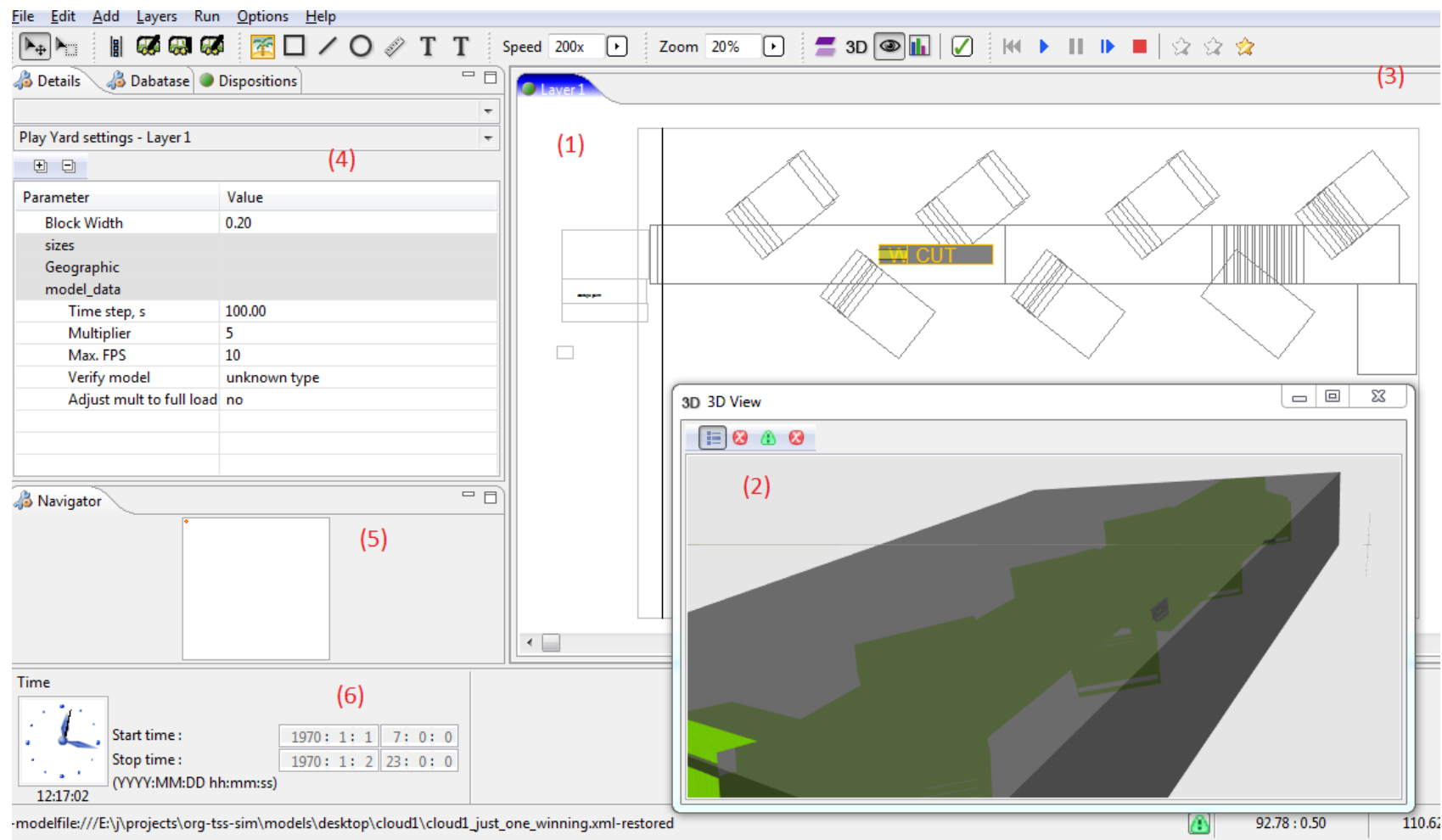

Fig. 4. The main window of MTSS system while running of simulation model of coal mining in flat-lying coal seam.

The model was created to visualize a new technology of coal-mining in flat-lying coal seam. This simulation model also allows receiving statistical results for usage of this technology. As patent describes, mining is done by frontal winning machine, paired with self-moving coal wagons. Patent describes the directions of cut of a flat-lying coal seam for the frontal winning machine. Simulation model of this process allows visualizing the process described.

For detailed simulation of longwall mining system we finished with next decomposition:

- Armored Face Conveyor (AFC).

- Shearer.

- Roof support sections.

Simulation model for longwall mining system can function if it is connected (in terms of MTSS) with the belt conveyor simulation model. Also this model requires a power supply chain, that means it will require a wire and power transformer facility model "connected” to it (in terms of MTSS).

The goal of creation of simulation of longwall mining system is:

- To create a smart, real-looking mines simulation system. Our organization is not in charge for the control systems for longwall automation, therefore the primary goal is to provide a simulation model that ensures efficient production.
- To investigate the possible pitfalls and bottlenecks of using different longwall configurations for different coal layers. In other words, to do simulation research of longwall system itself, detached from the rest of the mine simulation system.

The algorithm for longwall mining system simulation was done closer to the control algorithms of the real longwall mining system. Today our simulation contains one-way and two-way shearing (besides there are more shearing techniques combined from these two).

Figure 5 shows the simplest two-way shearing. In this case, shearer will mine the product while it moves in both directions. Roof support section will move itself forward (and AFC too) each time the shearer passed it. Then it will advance the simulation to the time defined, and then simulate the roof support sections movement. The amount of mined product will be moved to the AFC that will deliver it to the connected belt conveyor. Task will repeat these steps until the "done" or "postpone" conditions are achieved.

Task is "done" when shearer reaches the end of an AFC line. Task is "postponed" when belt conveyor is overloaded and cannot accept the next portion of product or gas level is not safe. During any of these steps, the simulation model of flatlying coal seam simulates roof fall (behind the roof support) and gas level increasing. Also ventilation simulated in a simple manner (remove gas from working area, with some defined speed). One-way shearing is to shear the product only in one direction. After the shearing path is over, the shearer will be 
returned to its starting position, and only then all roof supports advanced to the new position simultaneously.

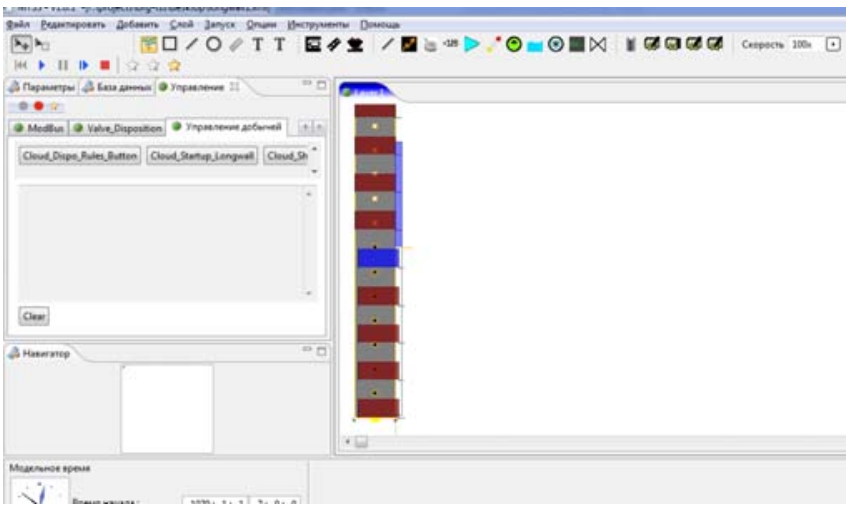

Fig. 5. The longwall shearer and roof support in two-way shearing.

In most cases, there is no need to simulate in details any technology like longwall or flat-lying coal mining, if it is used just as a source of a product for belt conveyor system, for example. All that is really needed in such cases are:

- To define that longwall or flat-lying coal mining is a source of a product for a big mining system like conveyor.

- To determine the performance of the longwall coal mining during some time period (working day, 8-hours time interval, 1-hour time interval). Note that emergency stops (like gas or coal dust) are already included in this statistical data.

The goals of simulation are:

- To predict how longwall or flat-lying coal seam mining automation will behave in details (i.e. movement of its parts depending on various situations in mines).

- To make a detailed visualization of mining process.

- To define how this mining will impact to the overall performance of the mines.

- To define scenarios of broken or temporarily inaccessible parts interactively [14].

The achievement of these goals requires a detailed decomposition of common longwall (or highwall) mining system and a detailed visualization of all its parts.

Figure 6 shows the hardware installation for the real "hardware-in-the-loop" with the combined model and the real control hardware for managing one of the belt conveyors presented in the model. The other conveyors are managed by simulation programs for these belt conveyors simulation models.

\section{CONCLUSION}

Detailed simulation of longwall system, connected with detailed simulation of flat-lying coal seam (or multiple flatlying coal seams), will allow the creation of models that will not only predict the behavior of big underground mining systems, but also the simulation of land subsidence while using longwall, especially with very heavy longwall systems that can cut 10-meters-high coal seams. The MTSS simulation system can be used not only for simulation of existing coal mining techniques but also for perspective robotized techniques. The library of elements is still growing. It provides the capability to create detailed simulation models of underground mining facilities, including belt conveyor systems, power supply, ventilation, and various coal face models. Such simulation models can be used both in solving "what-if" tasks and in hardware development for control systems.

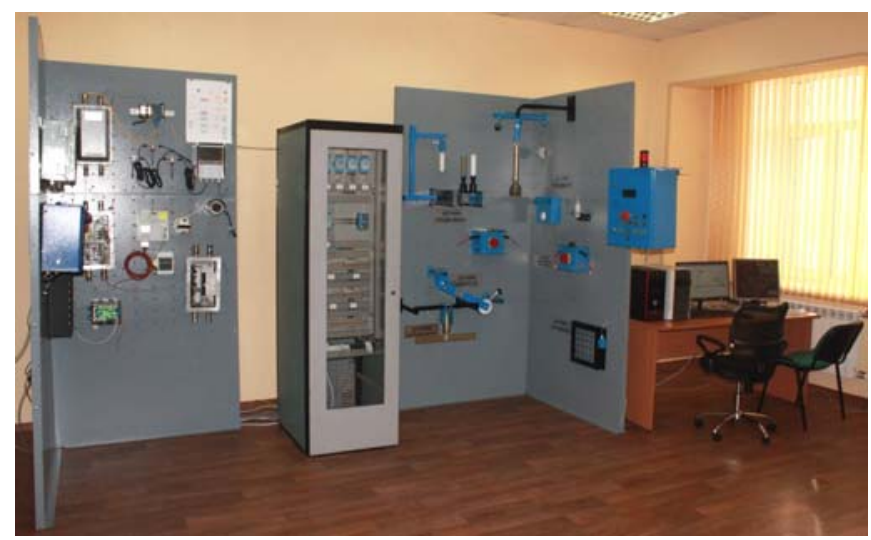

Fig. 6. Belt conveyor controlling hardware connected to the simulation model of whole mines factory.

\section{REFERENCES}

[1] J. R. Sturgul, "Modelling and Simulation in Mining-Its Time Has Finally Arrived”, Simulation, Vol. 76, No. 5, pp. 286-288, 2001

[2] M. S. Kizil, A. McAllister, R. Pascoe, "Simulation of Development in Longwall Coal Mines”, 11th Underground Coal Operators' Conference, University of Wollongong \& the Australasian Institute of Mining and Metallurgy, pp. 91-98, 2011

[3] J. Greberg, F. Sundqvist, "Simulation as a tool for mine planning”, 2th International Future Mining Conference, Sydney, New South Wales, pp 273-278, 2011

[4] D. Cai, E. Baafi, I. Porter, "Modelling a longwall production system using flexsim 3D simulation software", Twenty First international symposium on Mine planning and equipment selection, New Delhi, India, pp. 107-114, 2012

[5] I. Rascolean, C. Dura, "Efficient use of Production Factors in Pit Coal Extraction", 11th WSEAS International Conference on Automatic Control, Modelling \& Simulation, Stevens Point, Wisconsin, USA, pp. 140-145, 2009

[6] C. Meng, S. S. Nageshwaraniyer, A. Maghsoudi, Y. Son, S. Dessureault, "Data-driven Modeling and Simulation Framework for Material Handling Systems in Coal Mines”, Computers \& Industrial Engineering, Vol. 64, No. 3, pp. 766-779, 2013

[7] M. Fioroni, L. Santos, L. Franzese, I. Santana, G. Telles, J. Seixas, B. Penna, G. Alkmim, "Logistic Evaluation of an Underground mine Using Simulation”, 2014 Winter Simulation Conference, Savannah, GA, USA, pp. 1855-1865, 2014

[8] P. Šnapka, M. Mikušová, "Prevention of Crises Based on the Creation and Usage of Simulation Models", WSEAS Transactions on Business and Economics, Vol. 11, pp. 141-154, 2014

[9] V. Okolnishnikov, S. Rudometov, S. Zhuravlev, "Simulation environment for industrial and transportation systems", International Conference on Modelling and Simulation, Prague, Czech Republic, pp. 337-340, 2010 
[10] S. Rudometov, "MTSS simulation system", Patent FAP SB RAS, Novosibirsk, Russia, 2011, URL: http://fap.sbras.ru/node/2325 (In Russian)

[11] V. Okolnishnikov, "Development of Process Control Systems with the Use of Emulation Models”, International Journal of Mathematics and Computers in Simulation, Vol. 5, No. 6, pp. 553-560, 2011

[12] V. Okolnishnikov, S. Rudometov, S. Zhuravlev, "Simulation Environment for Development of Automated Process Control System in Coal Mining”, 2013 International Conference on Systems, Control, Signal Processing and Informatics (SCSI 2013), Rhodes Island, Greece, pp. 285-288, 2013
[13] V. Okolnishnikov, S. Rudometov, S. Zhuravlev, "Simulation Environment for Development of Automated Process Control System in Coal Mining”, International Journal of Systems Applications, Engineering \& Development, Vol. 7, No. 5, pp. 255-262, 2013

[14] A. Cirulis, E. Ginters, "Training Scenario Operations Realization in Virtual Reality Environment”, 13th WSEAS International Conference on Automatic Control, Modelling \& Simulation, Canary Islands, Spain, pp. 39-44, 2011 